\title{
The Ultrastructure of Megakaryocytes and Blood Platelets in the Rat Spleen '
}

\author{
SEONG S. HAN AND BURTON L. BAKER \\ School of Dentistry and Department of Anatomy, Medical School, \\ The University of Michigan, Ann Arbor, Michigan
}

\begin{abstract}
The cytoplasm of the megakaryocyte in the rat spleen possesses three zones, the perinuclear, intermediate and marginal. The perinuclear zone is characterized by the presence of Golgi apparatus, ribosomes, endoplasmic reticulum, and mitochondria. These organelles are found also in the more voluminous intermediate zone which in addition exhibits platelet granules and an extensive development of vesicles from smooth-surfaced endoplasmic reticulum to form demarcation membranes by coalescence. The marginal zone is almost devoid of the organelles and inclusions present elsewhere. Shedding of platelets appears to occur by extension of a paired demarcation membrane from the intermediate zone to the cell membrane and subsequent separation of its lamellae so that all of the essential organelles and inclusions of the intermediate zone may be included within the platelet. In addition, platelets contain vesicles which are probably pinocytotic in nature. Platelets are sometimes engulfed by the cytoplasm of phagocytic cells.
\end{abstract}

Numerous incidental observations on the ultrastructure of megakaryocytes and blood platelets have been reported (De Marsh et al., '55; Pease, '55; Rinehart, '55; Goodman et al., '57; Kisch, '57; Mizuno et al., '59; Jones, '60). A detailed description of the ultrastructure of megakaryocytes by Yamada ('57) confirmed the earlier description of Heidenhain (1894) based on observation with the light microscope. Yamada subdivided the cytoplasm of the megakaryocyte into three zones. The innermost or perinuclear zone consisted of a narrow band of cytoplasm immediately surrounding the nucleus; the middle or intermediate zone was wide and distinguished by the presence of the platelet demarcation membrane system; and the outer or marginal zone was narrow and made up of a finely granular ground cytoplasm. Mitochondria, small vesicles and endoplasmic reticulum were observed throughout the perinuclear and intermediate zones. The Golgi apparatus and centriole were found chiefly in the perinuclear zone and in the area of cytoplasm encompassed by the lobated nucleus.

Yamada described four stages in formation of the platelet demarcation membranes, namely the prevesicular, vesicular, membranous and residual. During the vesicular stage, vesicles about $400 \AA$ in diameter appeared in the intermediate zone and became aligned in rows. Fusion of these vesicles to form a system of paired membranes distingiushed the membranous stage. Liberation of platelets was believed to occur by extension of the demarcation membranes through the marginal zone to insertion into the plasma membrane with subsequent separation of the paired demarcation membranes. Following shedding of platelets the cell reverted to the residual stage.

This report is concerned with the numerous aspects of the ultrastructure of megakaryoctyes and platelets which merit additional study including the distribution of ribosomes, the origin and structure of platelet granules, ${ }^{2}$ the structure of mitochondria, and the structure and distribution of the Golgi apparatus.

\section{MATERIALS AND METHODS}

Six female Sprague-Dawley rats of 200 gm body weight were used. While the animals were under ether anesthesia, small pieces of spleen were excised and fixed for four hours in chilled 1 or $2 \% \quad \mathrm{OsO}_{4}$ buffered with $0.14 \mathrm{M}$ veronal acetate to $\mathrm{pH} 7.4$. Sucrose was added to the fixative to make a $4.5 \%$ solution. The tissues were dehy-

\footnotetext{
1 Supported in part by research grants from the National Institutes of Health A-131(C9) and from National Institutes of

2 The term "platelet granule" refers to the dense membrane-enclosed granules the diameter of which was approximately that of mitochondria.
} 
drated with ethanol and embedded in either butyl and methyl methacrylate (4:1) with $2 \%$ Luperco CDB as a catalyst or in a mixture of epoxy resin and anhydride, with DMP 30 [2,4,5-tri(dimethylaminomethyl) phenol] as the catalyst (Luft, '61).

During infiltration of the tissue, air was removed from the embedding medium by vacuum. The methacrylate was polymerized at $60^{\circ} \mathrm{C}$ for $12-24$ hours, whereas the epoxy mixture was cured at $35^{\circ}, 45^{\circ}$ and $60^{\circ} \mathrm{C}$ for 24 hours at each step. For tissues embedded in methacrylate, formvar coated grids were used. Sections from the epoxy resin blocks were mounted on girds covered by a thin layer of carbon. The latter sections were stained in a saturated solution of uranyl acetate for two hours.

\section{OBSERVATIONS}

\section{The megakaryocyte}

The megakaryocyte was distinctive because of the density and complexity of its cytoplasm. The cytoplasm was divisible into the three zones defined previously but additional ultrastructural features were observed.

Zonation. The marginal zone varied in width and usually lacked organelles and demarcation membranes. The cytoplasm contained a few ribosomes and vesicles and was of fairly uniform density (fig. 1). Contrary to Yamada, a few platelet granules were present (figs. 1 and 2). The plasma membrane showed frequent protrusions (figs. 2 and 5 ) as well as small invaginations.

The perinuclear zone consisted of a narrow region of cytoplasm immediately surrounding the nucleus which was quite different from the rest of the cytoplasm. In it were a few mitochondria, the Golgi apparatus, and frequent ribosomes which were both free and attached to endoplasmic reticulum (fig. 1). These structures were also characteristic of the cytoplasm enclosed by the nuclear lobes (the "endoplasm" of Heidenhain) (figs, 3,4 and 6). The marginal and perinuclear zones were generally devoid of demarcation membranes and platelet granules.

The intermediate zone contained the greatest volume of cytoplasm. It was sepa- rated from the perinuclear zone by an indistinct boundary (figs. 1, 3 and 6), whereas the coalescing vesicles and demarcation membranes separated it more sharply from the marginal zones (figs. 1 and 2). Portions of the intermediate zone were often encompassed by the lobated nucleus (figs. 3,4 , and 6 ). The intermediate zone varied considerably from cell to cell in thickness and in the pattern and degree of organization of its membranous components. The ground cytoplasm was dense and included mitochondria, vesicles of varying shapes and sizes, Golgi components, platelet granules, and ribosomes which were both free and attached to the endoplasmic reticulum.

Cytoplasmic organelles. The intermediate zone contained sparsely distributed small vesicles and tubules which possessed smooth external surfaces (figs. 2 and 4). Structurally these vesicles could not be distinguished from the smooth-surfaced endoplasmic reticulum of other types of cells. The vesicles varied greatly in size. The interior of the smallest vesicles was comparable to the ground cytoplasm in density. The larger vesicles were more empty. When present in large number the small vesicles appeared to line up and coalesce to form a long, paired membranous profile (figs. 3 and 5 ), which is the demarcation membrane (Yamada, '57). A pair of membranes then appeared to separate, forming an interior with low electron opacity (figs. 1,2,3 and 6). Close to the marginal zone the demarcation membranes tended to parallel the plasma membrane (fig. 1), while in the deeper region of the intermediate zone they followed the contour of the nucleus (fig. 3 ).

The round to ellipsoid mitochondria were small, ranging from 0.15 to $0.3 \mu$ in their narrow diameter. The interior was dense and contained only one or a few cristae which traversed the matrix in varying directions (figs. 1, 2, and 4).

The platelet granules were ovoid and occasionally elongated (figs. 1 to 6 ). They varied in size, their long axis ranging from approximately 0.3 to $0.7 \mu$. A limiting membrane enclosed a homogeneous interior which varied in density. Frequently only a portion of the granule was of high electron opacity, this part assuming a semilunar shape and lying against the limiting 
membrane (figs. 2 and 5) while the remainder of the matrix was less opaque and often contained tiny granules or round vesicles.

Endoplasmic reticulum was most frequent in the perinuclear zone and deeper portions of the intermediate zone (figs. 1 to 4). It was both smooth- and rough-surfaced. Free ribosomes, often appearing in small aggregates, exhibited a distribution similar to that of the endoplasmic reticulum. The Golgi apparatus was found in the perinuclear and intermediate zones (figs. 1, 4, and 6), and consisted of paired membranes with blind ends, small vesicles, and a few larger, less dense vacuoles. Material appeared between the membranes which was comparable in density and structure to the matrix of the platelet granules (fig. 1 ).

Nucleus. The envelope of the multilobated nucleus consisted of a double membrane, the outer one being continuous with the endoplasmic reticulum (figs. 1 and 3 ). The nucleoplasm contained fine electron dense granules which were distributed rather evenly throughout the nucleus, except for more central mottled areas which frequently were associated with nucleoli (fig. 6).

\section{The platelets}

Platelets appeared in groups between reticular cells and in the lumina of splenic sinuses (fig. 7). The platelets were pleomorphic. Their dense ground cytoplasm was like that of the marginal zone of the megakaryocyte and contained mitochondria, Golgi components and the platelet granules similar to those of the megakaryocyte. Rough-surfaced endoplasmic reticulum and free ribosomes appeared less frequently (fig. 12). Most striking were vacuoles of varying shapes and sizes which contained material of variable electron opacity. The lightest content was observed in the larger vacuoles which were peripherally located and occasionally opened to the outside (figs. 11 and 12). These graded over to smaller, more centrally located vesicles which were indistinguishable from those of the Golgi apparatus. The structure of the platelet granules was similar to that of the granules described previously in the megakaryocyte.
Frequently numerous platelets were found within a phagocytic cell (fig. 10) and had a more rounded contour than those located extracellularly. No degenerative structural changes were observed in these platelets which indicated that they were resistant to phagocytic action.

\section{DISCUSSION}

\section{The megakaryocyte}

The origin and structure of platelet granules. Based on an electron microscopic observation of normal and leukemic blood, bone marrow and other organs, Rinehart ('55) concluded that mitochondria transformed into platelet granules, since transitional forms between the two were observed, and both structures were of equal size. A similar conclusion was indicated by the description of transitional forms by Bernhard and Leplus ('55). Although the granules and mitochondria observed in the present study were of small size, the granules regularly lacked the characteristic limiting membranes of the mitochondria, and the matrix of the granules was usually somewhat denser than that of mitochondria. No clear-cut transitional forms were found.

On the other hand, from his study of megakaryocytes in the fetal liver, Jones ('60 and '62) claimed that megakaryocyte granules arise in the Golgi apparatus and described intermediate forms between the mature granules and Golgi vesicles. Support for his general concept was obtained from the present study since material was observed within the membrane-enclosed spaces of the Golgi apparatus, which in its density and structure was indistinguishable from the matrix of the platelet granules. Assuming that the substance of the granules contains protein, it is significant that the Golgi apparatus, endoplasmic reticulum, ribosomes and platelet granules were all associated together in the intermediate and inner zones. Ribosomes contain ribonucleoprotein, which in many cells serves as a template for protein synthesis (Palade and Siekevitz, '56). Thus, in megakaryocytes, ribosomes may be concerned not only with the production of new granules but also with reconstitution of 
new cytoplasm to replace that lost in the shedding of platelets.

Demarcation membranes. The term "endoplasmic reticulum" is defined loosely (Porter, '61), and has been used to encompass almost all intracytoplasmic membranes exclusive of those in the Golgi apparatus and mitochondria. In megakaryocytes the small vesicles which coalesce to form demarcation membranes could not be distinguished from smooth-surfaced endoplasmic reticulum. However, the membranes became more conspicuous as the space separating the membranes expanded. On these grounds, the demarcation membrane may be regarded as another specialization of the smooth-surfaced endoplasmic reticulum. This is contrary to the position of Yamada ('57) who looked upon the endoplasmic reticulum and demarcation membranes as distinctly separate systems.

\section{Platelets}

The hypothesis that the protoplasm of platelets is derived from the marginal $\mathrm{cy}$ toplasm of megakaryocytes appears valid because of the similarity in density and the rare occurrence of ribosomes and the rough-surfaced endoplasmic reticulum in the two locations. The occasional protrusion of the marginal cytoplasm of the megakaryocyte between reticular cells further suggests that a pinching off of the marginal zone actually takes place (Pease, '55). The abundance of platelet granules and other organelles in platelets compared with their low frequency in the marginal zone, supports Yamada's suggestion that, during platelet separation, demarcation membranes extend out toward the cell surface from the deep intermediate zone to include part of the latter as well as the marginal cytoplasm.

Since most of the common cytoplasmic organelles, including mitochondria, components of the Golgi apparatus, the endoplasmic reticulum, and ribosomes are present in platelets, the platelet can be regarded as a structure potentially capable of all cellular functions except those immediately dependent on the nucleus. The life span of platelets is estimated to be 4 to 10 days (Mizuno et al., '59; Odell and
McDonald, '61). Assuming that a cell requires the continuous support of a nucleus (Brachet, '57), the close positional relationship described between the platelet and phagocyte may indicate that the latter provides nucleus-conditioned support for the platelet in a manner similar to that described elsewhere for erythroblasts (Bessis and Breton-Gorius, '59) and plasma cells (Thiéry, 60, and Han, '61).

Structural characteristics of the mitochondria have a bearing on the biochemical properties of platelets. As compared with the mitochondria of most other cells, those in platelets are small, few in number, and possess few cristae. The magnitude of these characteristics appears to be directly proportional to the respiratory activity of a cell. Thus it may be inferred that platelets do not utilize extensively the tricarboxylic acid cycle for the production of energy. Indeed, Gross ('61) has shown that under aerobic conditions glycolytic activity is predominant.

Transport of materials across the surface of platelets was clearly indicated by the opening up of peripheral vacuoles to the outside. Bessis ('57) described the presence of contractile and pinocytotic vacuoles in the platelets of the frog. Braunsteiner ('61) and Policard et al. ('59) also noted the presence of large vacuoles in platelets observed with the electron microscope. Static photographs utilizing the electron microscope do not show whether vesicles and vacuoles are indicative of pinocytosis or secretion. As is true of many other types of cells, the contents of these vacuoles showed great variation in density which might be suggestive of either condensation of engulfed material or liquefaction of stored secretion prior to liberation. The opening of vacuoles in platelets to the outside has not been seen previously. The presence of serotonin (Jaques and Fisher, '60) and acetylcholinesterase ( $\mathrm{Za}$ jicek and Datta, '53) in platelets has been demonstrated repeatedly. Since in most other protein-secreting cells secretory precursors are stored in the form of membrane-enclosed granules, these substances may be concentrated in the granules of megakaryocyte and platelet and undergo some liquefaction prior to or at the time of release. 


\section{LITERATURE CITED}

Bernhard, W., and R. Leplus 1955 La méthode des coupes ultratfines et son application à l'étude de l'ultrastructure des cellules sanguines. Schweiz. med. Wchnschr, 85: 897-899.

Bessis, M. 1957 Microscopie de phase et microscopie electronique des cellules du sang. Biol. Méd., 46: 239-288.

Bessis, M., and J. Breton-Gorius 1959 Nouvelles observations sur l'ilot érythroblastique et la rhophéocytose de la ferritine. Rev. Hémat., 14: 165-197.

Brachet, J. 1957 Biochemical Cytology. Academic Press, New York.

Braunsteiner, H. 1961 Electron microscopy of blood platelets. In: Blood Platelets. Ed. S. A. Johnson, R. W. Monto, J. W. Rebuck and R. C. Horn, Jr. Little, Brown and Company, Boston, pp. 617-628.

DeMarsh, Q. B., J. Kautz and A. G. Motulsky 1955 An electron microscope study of sectioned platelets and megakaryocytes. J. Clin. Investig., 34: 929-930.

Goodman, J. R., E. B. Reilly and R. E. Moore 1957 Electron microscopy of formed elements of normal human blood. Blood, 12: 428-447.

Gross, R. 1961 Metabolic aspects of normal and pathological platelets. In: Blood Platelets. Ed. S. A. Johnson, R. W. Monto, J. W, Rebuck and R. C. Horn, Jr., Little, Brown and Company, Boston, pp. 407-421.

Han, S. S. 1961 The ultrastructure of the mesenteric lymph node of the rat. Am. J. Anat., 109: 183-225.

Heidenhain, M. 1894 Neue Untersuchungen ueber die Centralkoerper und ihre Beziehungen zum Kern- und Zellenprotoplasma. Arch. mikr. Anat., 43: 423-758.

Jaques, L. B., and L. M. Fisher 1960 Platelet serotonin as a factor in hemostasis. Arch. Intern. Pharmacodyn., 123: 325-333.

Jones, O. P. 1960 Origin of megakaryocyte granules from Golgi vesicles. Anat Rec., 138: 105-114.
1962 Normal granulopoiesis of the megakaryocyte. Proc. VIII Congr. Europ. Soc. Haemat., Article no. 429.

Kisch, B. 1957 Electron microscopy of blood platelets. Exptl. Med. Surg., 15: 272-288.

Luft, J. H. 1961 Improvements in epoxy resin embedding methods. J. Biophys. Cytol., 9: 409414.

Mizuno, N. S., V. Perman, F. W. Bates, J. H. Sautter and M. O. Schultze 1959 Life span of thrombocytes and erythrocytes in normal and thrombocytopenic calves. Blood, 14: 708-719.

Odell, T. T. Jr., and T. P. McDonald 1961 Life span of mouse blood platelets. Proc. Soc. Exptl. Biol. Med., 106: 107-108.

Palade, G. E., and P. Siekevitz 1956 Liver microsomes. An integrated morphological and biochemical study. J. Biophys. Biochem. Cytol., 2: 171-200.

Pease, D. C. 1955 Marrow cells seen with the electron microscope after ultrathin sectioning. Rev. Hemat., 10: 300-313.

Policard, A., A. Collet and S. Prégermain 1959 Etude infrastructurale des thrombocytes du sang circulant chez le rat. Bull. Micr. Appl., 9: 26-29.

Porter, K. R. 1961 The ground substance; observations from electron microscopy. In: The Cell, Vol. II. Ed. J. Brachet and A. E. Mirsky. Academic Press, New York, pp. 621-675.

Rinehart, J. F, 1955 Electron microscopic studies of sectioned white blood cells and platelets. Am. J. Clin. Path., 25: 605-619.

Thiéry, J. P. 1960 Microcinematographic contributions to the study of plasma cells. In: Ciba Foundation Symposium on Cellular Aspects of Immunity. Ed. G. E. W. Wolstenholme and $M$. O'Connor. Little, Brown and Company, Boston, pp. 59-91.

Yamada, E. 1957 The fine structure of the megakaryocyte in the mouse spleen. Acta Anat., 29: 267-290.

Zajicek, J., and N. Datta 1953 Investigation on the acetylcholinesterase activity of erythrocytes, platelets and plasma in different animal species. Acta hemat., 9: 115-121. 


\section{PLATE 1}

EXPLANATION OF FIGURES

1 Cytoplasm of a megakaryocyte. The marginal zone (MZ) is made up of rather dense cytoplasm. Demarcation membranes (DM) separate it from the intermediate zone (I) in which are the endoplasmic reticulum with attached ribosomes, mitochondria (M), platelet granules (S) and a Golgi apparatus. The material enclosed in the Golgi membranes (G) is similar in density to the contiguous granule (S) and to those located farther away. The perinuclear zone (P) consists of a narrow band of cytoplasm surrounding the nucleus. The nuclear envelop shows a bleb $(B) . \times 19,800$.

2 Peripheral portion of megakaryocyte cytoplasm. The surface membrane covers part of a reticular fiber (F). The cytoplasm of the megakaryocyte is denser than that of a reticular cell (RC). The structure of the platelet granules (S) varies greatly. $\times 14,900$. 


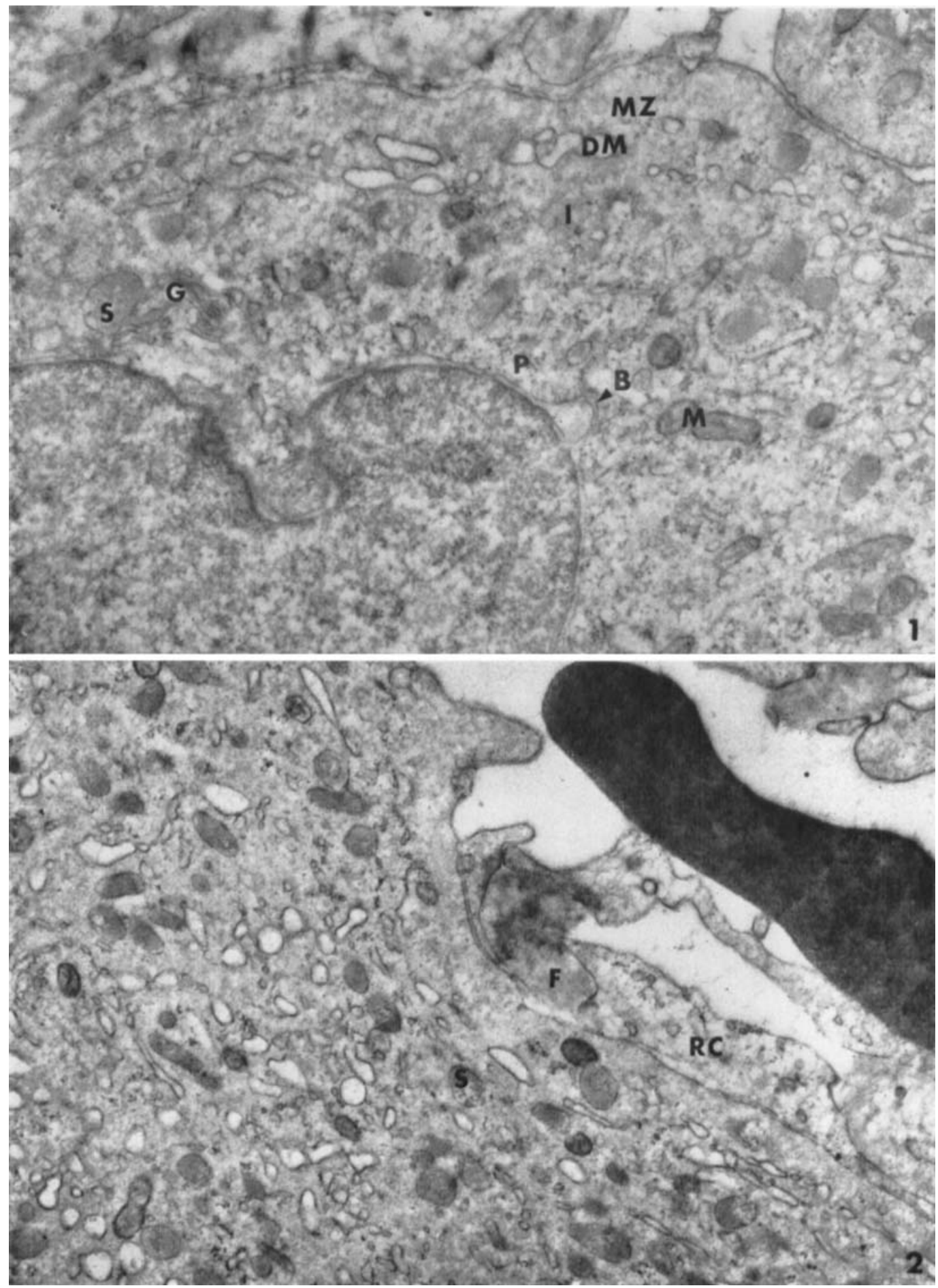


PLATE 2

EXPLANATION OF FIGURES

3 Deep cytoplasm of a megakaryocyte. The perinuclear zone contains many ribosomes. The intermediate zone is rich in demarcation membranes and vesicles, and extends deep into the region between nuclear lobes, the "endoplasm" (INC). Demarcation membranes tend to be oriented in conformity to the nuclear contour. $\times 9,000$.

4 A portion of the megakaryocyte endoplasm. The characteristic cytoplasm of the intermediate zone with demarcation membranes and platelet granules (S) extends into this region. Golgi elements (G), endoplasmic reticulum, ribosomes and mitochondria are numerous. $\times 17,600$. 

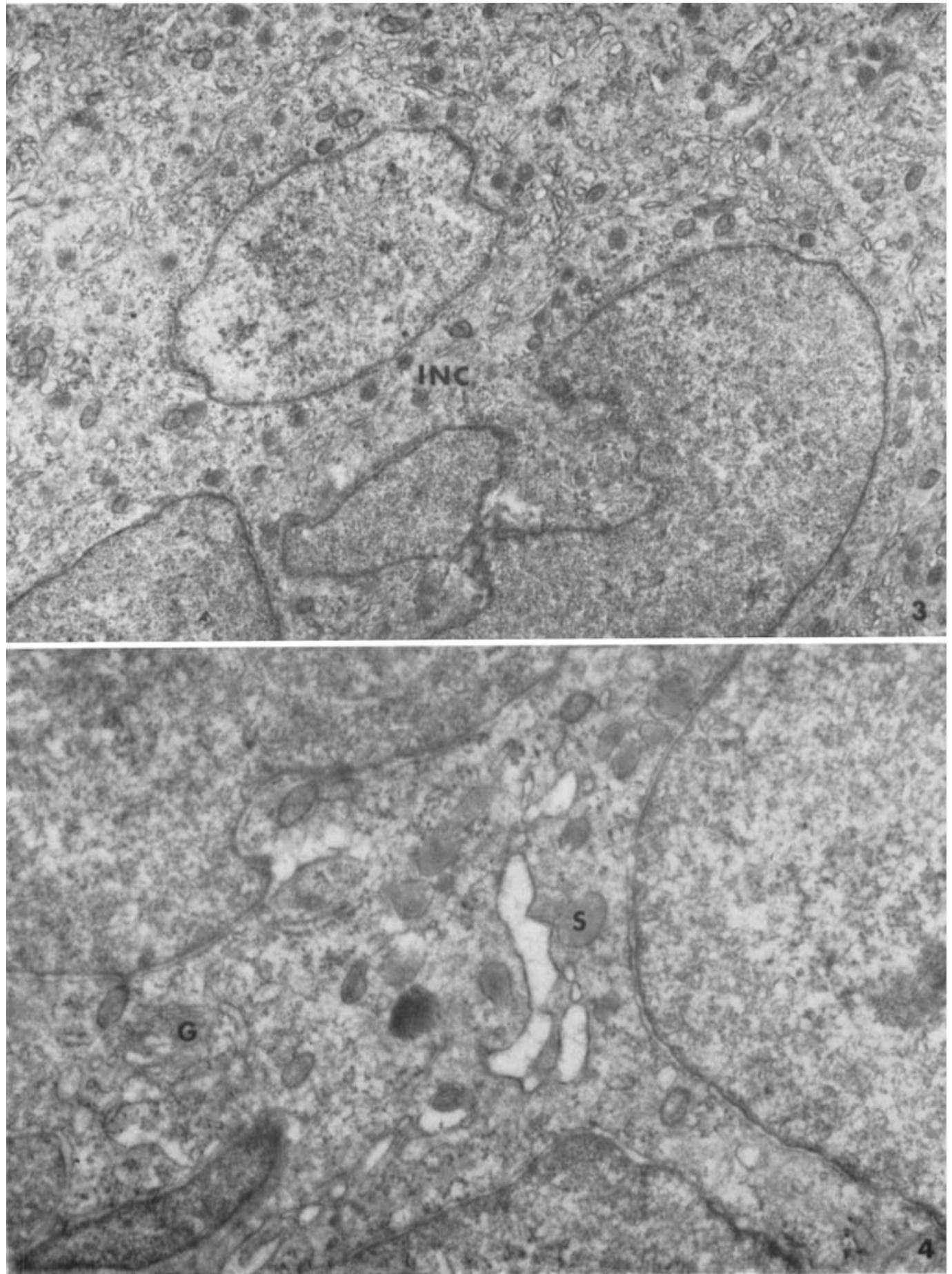
PLATE 3

EXPLANATION OF FIGURES

5 The marginal cytoplasm of a megakaryocyte protrudes into a splenic sinus through an interruption in the basement membrane (BM) and reticulo-endothelial cell lining ( $R C$ ). The smooth-surfaced vesicles (SER) are lined up and appear to be coalescing to form demarcation membranes. $\times 12,000$.

6 The nuclear region of a megakaryocyte. Extensive nuclear lobation is evident. Small homogeneous, nongranular areas $(\mathbf{H})$ are scattered throughout the nucleoplasm, often being associated with nucleoli. The perinuclear zone contains abundant ribosomes, Golgi apparatus, and more rough-surfaced endoplasmic reticulum than other parts of the cell. $\times 7,800$. 

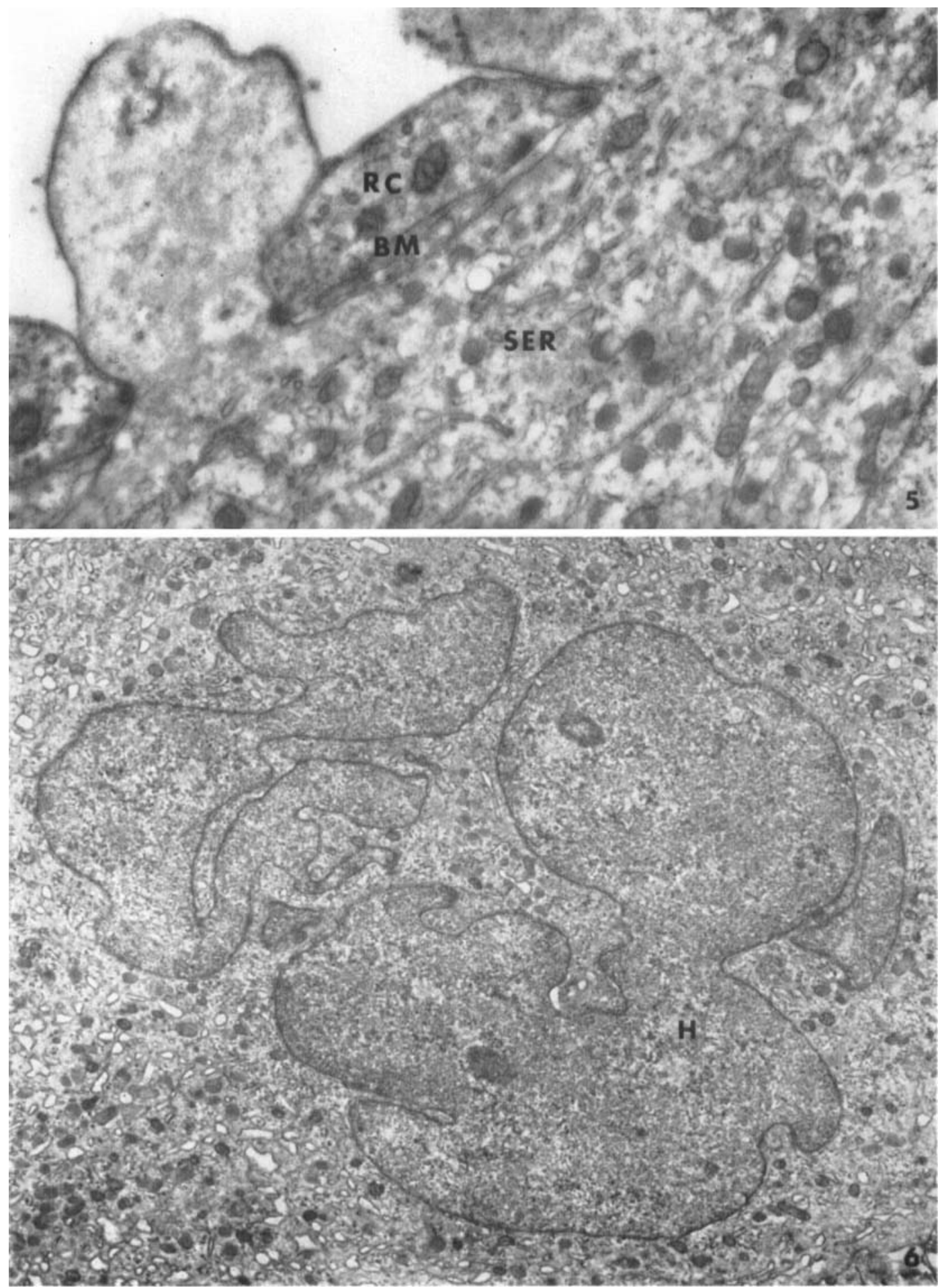
PLATE 4

EXPLANATION OF FIGURE

7 A group of platelets in the red pulp of the spleen, illustrating their pleomorphism and numerous cytoplasmic projections. They contain platelet granules, Golgi elements, smooth-surfaced vesicles, mitochondria and vacuoles. The rough-surfaced endoplasmic reticulum ( $R$ ) and ribosomes are not abundant. The ground cytoplasm is of higher electron density than that of adjacent reticular cells. $\times 21,000$. 


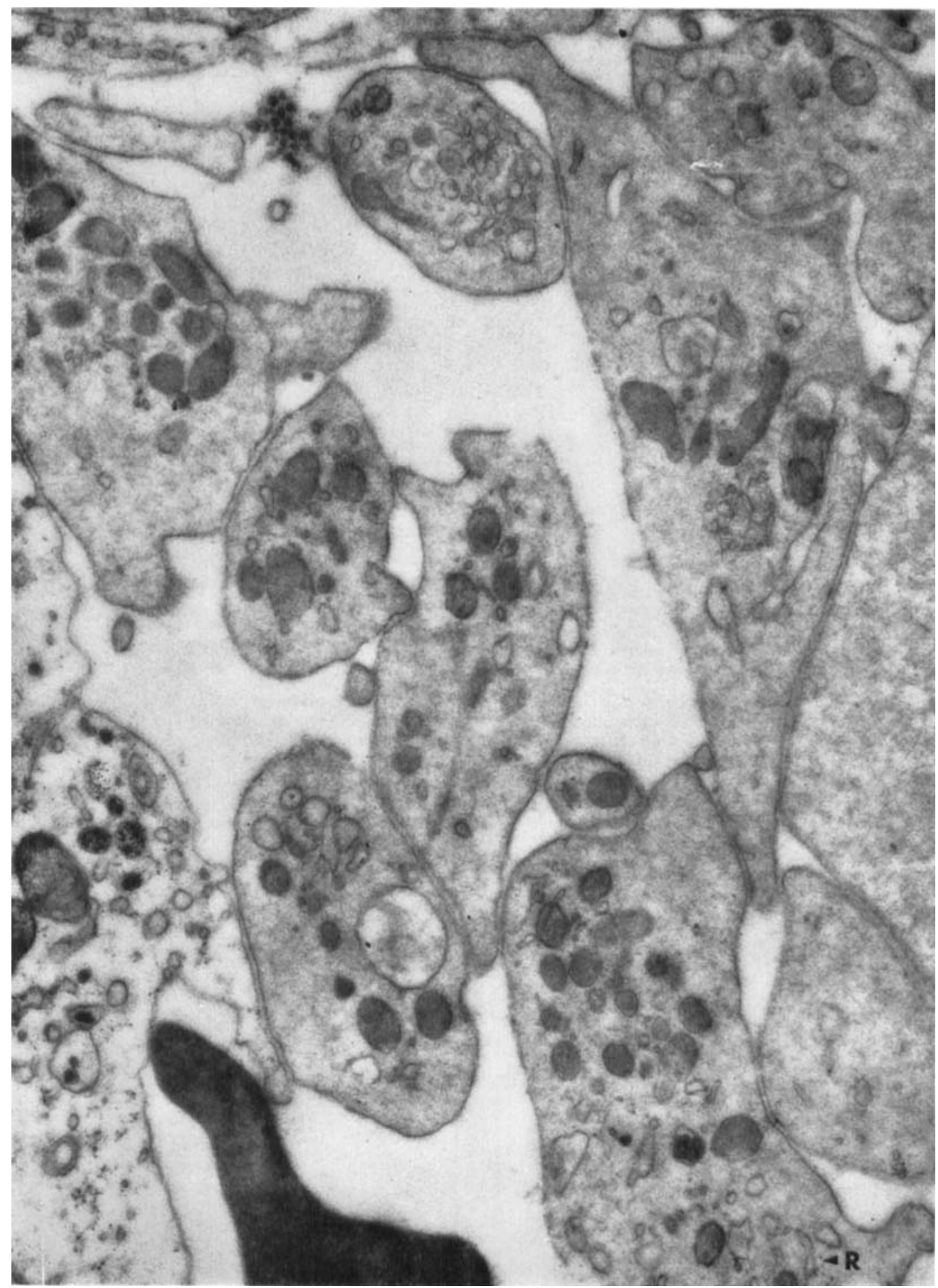


PLATE 5

EXPLANATION OF FIGURES

8 Platelets showing Golgi elements (G), vesicles (V) and granules (S). Mitochondria are small, round and possess few cristae. $\times 16,000$.

9 A platelet with granules of different shapes and sizes. The limiting membrane of the elongate granule at the left appears to be continuous with the membranous wall of a vacuole (arrows). The mitochondrial matrix is more uniform in structure and less dense than that of platelet granules. $\times 18,400$.

10 A phagocytic cell which encompasses several platelets in its cytoplasm. The membranes intervening between phagocyte and platelet cytoplasm are interrupted. No clear signs of degeneration are seen in the platelets. $\times 6,000$. 


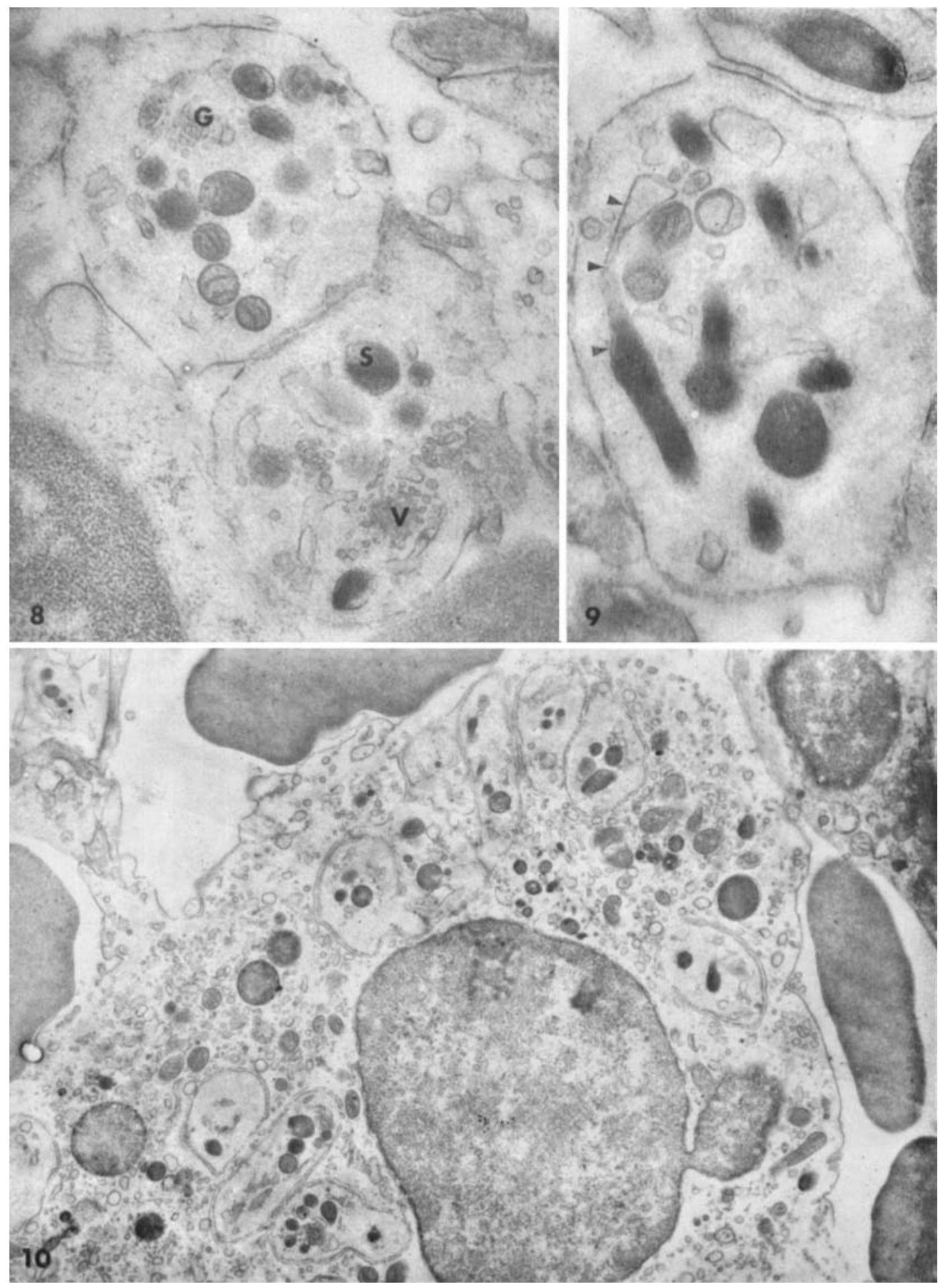


PLATE 6

EXPLANATION OF FIGURES

11 A platelet showing large vacuoles. The peripheral ones appear to have established continuity with the exterior by an opening at the surface membrane (arrows). One of the more centrally located vacuoles contains an electron dense granule in it. $\times 21,000$.

12 A platelet showing mitochondria, platelet granules (S), vacuoles and profiles of endoplasmic reticulum associated with ribosomes. Note the transitional forms between the large vacuoles (V) and smaller vesicles, many of the latter probably being Golgi components. Free ribosomes are also present. $\times 42,000$. 


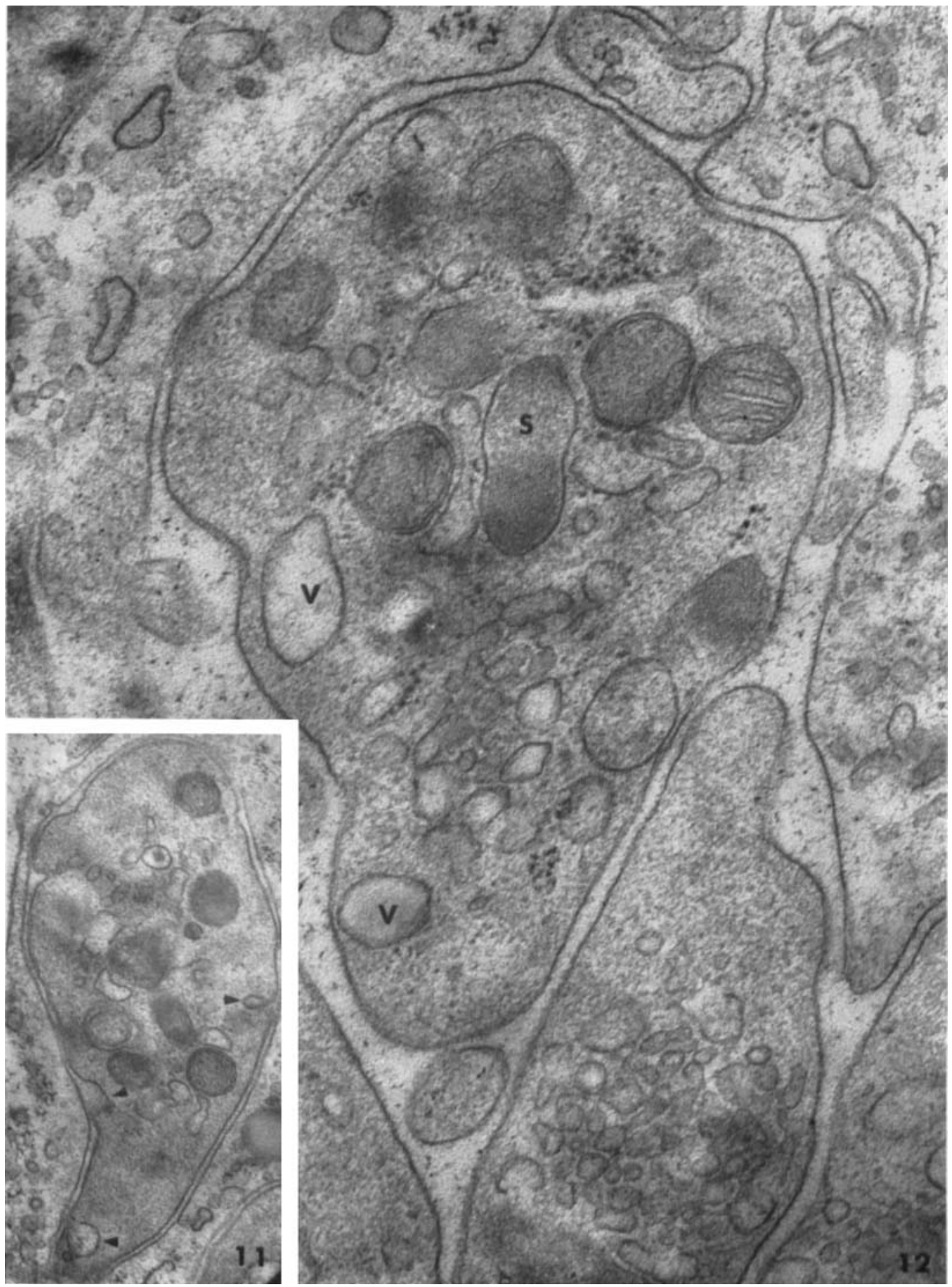

